\title{
Financial Analysis Method Based On Astrology, Fibonacci, And Astronacci To Find A Date Of Direction Inversion Base Information Technology - Jci And Future Gold Prices
}

\author{
Gema Merdeka Goeyardi, Ghozali Imam, Hamdy Hady \\ Faculty of Economics \& Business, Indonesia Persada University, Jakarta 10430, Indonesia \\ Email : correspondent.author@gmail.com
}

Article History: Received: 11 January 2021; Accepted: 27 February 2021; Published online: 5 April 2021

\begin{abstract}
The purpose of this research is to analyze and obtain empirical evidence knowing the exact time to be predicted determining the reversal date of the JCI (Jakarta Composite Index) price and Gold prices can use the method of Astrology, Fibonacci, Astronacci. The method used in this research is descriptive and explanatory methods. Descriptive method is used to make steps Astrology, Fibonacci, and Astronacci methods to find the reversal date of the JCI and the price of Gold in the future. While the explanatory method is used to apply Astrology, Fibonacci, and Astronacci methods using historical data (in 20082017), JCI and Gold prices. Data used in this study for 1 decade is January 1, 2008 to December 31, 2017. Based on the three methods, the reversal opportunity of both the JCI and the highest Gold price using the Astronacci method rather than astrology or Fibonacci alone.
\end{abstract}

Keywords: Astrology, Astronacci, Bearish, Bullish, Reversal, Fibonacci, Information Technology, Gold, Jakarta Composite Index, IDX, Time

\section{Introduction}

Investment is one way to utilize funds for the future. The most important consideration in investing is the inflation rate. There are various investment options in the real sector (such as gold bullion or jewelry, housing, land) and the financial sector (such as savings, deposits, mutual funds, gold certificates, stocks, futures contracts, foreign exchange). Stocks and Gold are examples of financial sector investments whose risk can be controlled by investors. Stocks in Indonesia are reflected by the Jakarta Composite Index (JCI).

Based on Lusia \& Muntari (2016: 124), the advantages and risks of the monthly JCI using the initialmonth buy price and month-end selling price references are $1.172 \%$ per month with a risk of 6.128 . Meanwhile, with the optimization of the profits obtained by $8,558 \%$ per month with a risk of 4,222 . So that a good strategy can increase profits and reduce risks. The price of gold futures from 2000 - 2016 averaged a maximum profit of $9.092 \%$ per month with a risk of 5.238. The analysis that is often used in making buying and selling decisions is fundamental analysis and technical analysis. However, the two analyzes do not reflect the actual conditions.

Fundamental or technical analysis also has the opportunity to make investors lose because they don't know the right time to buy and sell. This follows the Dow Theory by Charles Henry Dow (perfected by Robert Rhea in 1932: 57) which explains that stock prices move in a trend and are not random, have repetitive cycles that can be time mapped. So even though fundamentally the stock price can be said to be cheap, it has a big risk if it is not bought at the right time cycle.

Past price movements form a pattern that can be used to predict price increases or decreases. However, many predictions are wrong based on past price movement patterns. Determination of the right time to buy and sell is strongly influenced by the date when the price will stop rising then reverse direction to fall or vice versa the date when the price will end its weakening and a rebound occurs (called a reversal date).

By knowing the date of the reversal, investors will avoid big losses and can make purchases and sales on time without having to wait too long to make a profit. The correct timing can be predicted using financial Astrology and Fibonacci. Financial astrology methods are used to predict the long term by looking at history and make mathematical predictions based on patterns relative to astronomical events. The method of financial astrology has been used since 463 BC. Then in 1992, 1994, and 2008, a magazine with the name Wall Street Forecaster was named as one of the top forecasters on Wall Street because it used the method of financial astrology. Time analysis using financial astrology is also used by well-known figures who are successful in the financial market, namely William Delbert Gann, George Bayer, and JP Morgan. JP Morgan quotes "Millionaires don't use astrology, billionaires do". 
Research on astrology in the case of stocks and commodities is Pesavento (1997); Bucholtz (2013: 89); Dichev \& Janes (2001: 72); Yuan, Zheng, \& Zhu (2006: 341); and Floros \& Tan (2013: 231). Pesavento (1997: 154) examines 5 Astrology factors (moon phase, moon declination, planet aspect, planet ingress, and retrograde) in stock and commodity markets. Pesavento concludes several trading strategies for rising and falling prices based on Astrology factors.

While Chaudhari \& Shah (2012: 238) examined the effect of the conjunction between the sun as a planet and the zodiac sign on the increase or decrease in the price of the Bse Senseive Index (Bse Sensex). One of the methods used to examine whether there is an effect of planets and zodiac signs on price movements is chi-square. The Chi-square test is also used by Chaudhari \& Shah (2013: 67) to examine whether there is an effect of the lunar conjunction with the zodiac sign on the Bse Sensex price movement. The Chi-square test is a suitable method to test the significance of the effect of Astrology aspects on stock reversal and Gold in this study.

There is also research that examines the effect of Astrology with reversals on Gold, namely Merriman (2015: 147). Merriman defines a reversal as a day where there is an increase or decrease of more than equal to $4 \%$ of the low. However, the reversal theory does not describe the reversal of the price direction referred to in the study. The table below presents empirical data on stock price movements from February 2017 to March 2017. During this period, there were 4 reversals from JCI, which occurred on February 13, 22 and 10, and March 20, 2017. This provides an illustration, only on certain dates related to the Astrology movement a stock price reversal occurs in an observed period.

This research has analyzed JCI and the price of Gold using Astrology, Fibonacci, and Astronacci methods to determine the date of future reversal. This study, limiting the Astrology factors used includes moon phase, moon declination, planet aspect, ingress planet, and retrograde.

\section{LITERATURE REVIEW AND PREVIOUS RESEARCH}

\section{Literature Review}

This research is about Financial Analysis Methods Based on Astrology, Fibonacci, and Astronacci to find the reversal date of JCI and the price of Gold in the future. The theoretical basis for using the three methods to determine the reversal date is Dow Theory. In addition, a review of previous theories and research on financial astrology, Fibonacci, price reversals, JCI and Gold is also needed.

Grand theories that underlie the use of Astrology factors, Fibonacci, and Astronacci are the capital market theory and Dow Theory. The capital market theory explains the function of the capital market and about the existence of agencies or institutions that play a role in the capital market (Zulfikar, 2016: 79). Dow Theory by Charles Henry Dow (perfected by Robert Rhea in 1932: 169) which explains that stock prices move in a trend, not random, and have repetitive cycles that can be mapped over time. The repetition cycle referred to in this study is the Astrology, Fibonacci, and Astronacci factors.

\section{The Capital Market Theory}

One of the definitions of the capital market is described in the Capital Market Law No. 8 of 1995 concerning the Capital Market, namely activities related to public offerings and securities trading, public companies related to securities issued by them, and institutions and professions related to securities. The capital market has two functions for the country's economy. The first function is a means of financing a business or company to obtain funds from the investor community. So that companies can carry out business development, expansion, and additional working capital. The second function of the capital market is to become a means for society to. investing in financial instruments such as stocks, bonds, and mutual funds. The capital market has characteristics compared to other types of markets, namely it has a long term, profits from dividends and capital gains, and the executors are securities companies and stock exchanges (Zulfikar, 2016: 56).

\section{Dow Theory}

Dow theory put forward by Charles Henry Dow (refined by Robert Rhea in 1932) which explains that stock prices move in a trend and are not random, it has repetitive cycles that can be mapped over time. So even though fundamentally the stock price can be said to be cheap, it has a big risk if it is not bought at the right time cycle. So even though fundamentally the stock price can be said to be cheap, it has a big risk if it is not bought at the right time cycle. Dow Theory has three movements that can all take place at the same time, namely the Primary Trend; Secondary Reaction, and Daily Fluctuation. 


\section{Financial Astrology}

Financial astrology is defined as the study of the influence between the movements and interactions of the planets and market behavior. Weingarten (2000: 127) states that financial astrology (which studies psychological knowledge and time) is as important as technical and fundamental analysis in predicting market behavior. There are five important points of financial astrology, namely Astrology is more than one and a half of the market, Astrology is mathematical psychology based on astronomy, Astrology can be a telescope and/or microscope, the market has a horoscope, and the first rule we will pay attention to the Christmas chart of the subject you want to study. Some of the horoscope systems used in financial astrology include moon phase, moon declination, planet aspect, planet Ingress, and retrograde.

Moon Phase

The moon's phase is determined by the configuration of the earth, moon, and sun positions. The time it takes to achieve the same two phases in succession, for example from full moon to the next full moon, is called the synodic period. One synodic period lasts 29.5 days. In a calendar that uses the lunar circulation as the benchmark, the $1^{\text {st }}$ is taken at the time of the new moon or the dead month. The new moon occurs when the moon is between the earth and the sun, so that no sunlight can be reflected from the moon to reach the earth. Then the moon moves around the earth, the longer the moon's surface is illuminated (Admiranto, 2009: 196).

\section{Moon Declination}

The centreline from the earth to the centre of the moon can be drawn as in Figure 2.2. Whereat any time, the lines cut between the earth's surface especially on the ground. Moon declination is a background that is formed and can change over time. If the moon's orbit is at Earth's equator, moon declination is always $0^{\circ}$.

Planet Aspect

There are 9 planets that revolve around the sun $\odot$ namely Mercury $\not$, Venus $\varnothing$, Earth $\bigoplus$, Mars $\sigma^{x}$, Jupiter ${ }^{4}$, Saturn $\hbar$, Uranus $\uplus_{\text {, }}$, Neptune $\Psi$, and Pluto ${ }^{\dagger}$. Aspect is the geometric angle that occurs between the two planets. This study follows Pesavento (1997) which uses the earth's point of view as the center (geocentric) because it is the most reliable from the trader's point of view. The synodic period on the planet aspect is the time interval between two planets that meet in the conjunction $\sigma^{\sigma}\left(0^{\circ}\right)$ and walk up sextile $*\left(60^{\circ}\right)$, square $\square$ $\left(90^{\circ}\right)$, trine $\Delta\left(120^{\circ}\right)$, opposition $0^{\circ}\left(180^{\circ}\right)$ and come back to the conjunction.

Each planet surrounds each zodiac (the sign of the imaginary circle) (Pesavento, 1997: 97). When the planets move into the new zodiac (house) it is called the ingress planet. According to Pesavento (1997: 98), the influence between the Ingress planet and the stock market gives more attention when several planets are in the same zodiac sign. For example, in August 1987 (the five planets are in the Leo sign) the stock market was at its peak. October 1974 (four planets are in the Virgo sign), the stock market is at a low.

\section{Retrograde}

Retrograde movements of planets occur when the planet moves faster than the other planets in its orbit. The planet's motion looks like it's backward, but it's not. Retrograde in the market illustrates that investors also withdraw or temporarily leave the market (Merriman, 1982). There are 6 points in the retrograde, namely (1) the sun and moon are never retrograde or stationary, (2) Mercury is retrograde for 24 days and is stationary about 1 day before and after, (3) Venus is retrograde for 42 days and stationary 2 or 3 days before and after, (4) Mars is retrograde for 80 days and stationary 2 or 3 days before and after, (5) Jupiter is retrograde for 120 days and stationary for about 5 days before and after, (6) Mercury, Venus, Mars, and Jupiter retrograde has an effect on price action. The reason why this happens is still unknown, but traders should be careful at that time. (Pesavento, 1997: 78).

The Fibonacci sequence was discovered by Leonardo 'Fibonacci' da Pisa, a mathematician who lived in 1175 (Fischer, 1993). The Fibonacci number sequence includes $0.1,1,2,3,5,8,21,34,55,89,144,233,377, \ldots$ etc. The Fibonacci sequence of numbers has the property of addition and multiplication. Through the analysis of Fibonacci, and the ratio of the Golden ratio and phi can prove that the market moves according to natural laws and we must cooperate with basic principles rather than assuming something in price data (Brown, 2008: 197).

Fibonacci ratios are good for forecasting correction targets or for analyzing the expansion of price targets. Expansion occurs in markets that are run-away. Investors should enter at the end of the expansion is the safest strategy on Elliott's concept (Fischer, 1993: 78). 


\section{Reversal}

A price reversal describes a change in trend or price direction. Pring (2014: 123) states that the basis of the trend principle which can be used in identifying reversals is the peak and trough progression. Reversal is indicated by the increasing and decreasing of peak and trough. According to Charles Dow's theory, the market moves upward in series waves, where each collection and reaction is increasing compared to the previous period.

JCI

JCI is an indicator of or reflection of stock price movements. It is used as a guide for investors to invest in the capital market, especially stocks. JCI is an index that uses all listed companies as a component of the calculation. In order to describe JCI in the fair market condition, the Indonesian Stock Exchange has the authority to issue and or not include one or more Listed Companies from JCI calculations. The basis for consideration is, among others, if the number of shares of the Listed Company which are owned by the public (free float) is relatively small while the market capitalization is large enough so that the change in the Listed Company's share price has the potential to affect the fairness of JCI's movement.

Gold

Gold is a chemical element with the symbol Au (from Latin: aurum) and atomic number 79. From all the precious metals, gold is the most popular commodity for investment. Many people keep gold in the form of gold coins or bars as a hedge against inflation or other economic disturbances. According to ISO 4217, the gold currency code is XAU.

In trading on world commodity exchanges, the unit used to trade gold is the troy ounce (toz) and is listed in US dollars (therefore known as XAUUSD). The spot gold price and the gold futures contract price have a very high correlation (Uludag \& Lkhamazhapov, 2016: 157). This is proven by using the corrected Dynamic Conditional Correlation (cDCC) model on spot gold data and futures contracts in Russia. In addition, the price of gold futures from 2000 - 2016 averaged a maximum profit of $9.092 \%$ per month with a risk of 5,238 (Lusia \& Muntari, 2016: 291).

\section{Previous Researches}

Pesavento (1997: 154) examines 5 Astrology factors (moon phase, moon declination, planet aspect, planet ingress, and retrograde) in stock and commodity markets. The five aspects of their influence on stock and commodity markets have been described in the previous chapter. He concluded several trading strategies for rising and falling prices based on Astrology factors. However, Pesavento did not explain how to determine the Astrology factors to be used. Even though there are 305 possible out of 5 Astrology factors ( 5 possible moon phases, 3 possible moon declination, 180 possible planetary aspects, 108 possible ingress planets, and 9 possible retrogrades).

How to determine the Astrology factor is described in the book "The Bull, The Bear and The Planet: Trading the Financial Markets Using Astrology" by Bucholtz (2013: 231). There are 5 steps in determining the Astrology factor, namely (1) finding the first trading date, (2) studying carefully and recording the planet aspect when the first trading date occurred, (3) determining which aspects have full power in the trading or investing strategy, (4) looking for a historical list of the date of the occurrence of major aspects in the past several years, (5) looking for the history of stock charts from previous years.

Testing in determining the effect of Astrology aspects on stocks was investigated by Dichev \& Janes (2001); Yuan, et. al. (2006); Floros \& Tan (2013); and Chaudhari \& Shah (2012 and 2013). Dichev \& Janes (2001) use the moon phase as an Astrology factor. He divides the data into 2 categories, namely full moon and new moon. The study explained that the benefit of 15 days around the new moon is twice that of the 15 days around the full moon based on the t-test. Yuan et al. (2006) used the TGARCH model in looking for the relationship between efficient market theory, related calendar effects, and investor mood based on moon phases. Floros \& Tan (2013) regressed the daily profit of shares based on the moon phase.

Meanwhile, Chaudhari \& Shah (2012) examined the effect of the conjunction between the sun as a planet and the zodiac sign on the increase or decrease in the price of the Bse Senseive Index (Bse Sensex). One of the methods used to examine whether there is an effect of planets and zodiac signs on price movements is chi-square. The Chi-square test was also used by Chaudhari \& Shah (2013) to examine whether there was an effect of the lunar conjunction with the zodiac sign on the Bse Sensex price movement. 
There is also research that examines the effect of Astrology with reversals on Gold, namely Merriman (2015). Merriman defines a reversal as a day where there is an increase or decrease of more than equal to $4 \%$ of the low. However, the reversal theory does not describe the reversal of the price direction referred to in this study.

This study examines financial analysis methods based on Astrology, Fibonacci, and Astronacci to find JCI reversal dates and future Gold prices. The idea of this research arose because of experiments that have been carried out by researchers for almost 10 years (starting in 2009). Researchers experimented with Astrology factors, Fibonacci, and Astronacci to find reversal dates for JCI, gold, stocks, and others. However, it has not been recognized by most scientists, especially in Indonesia. Therefore, this research is a form of proof for scientists in Indonesia.

In this study, the author tries to make conclusions from various theories where the reversal is the occurrence of a higher high twice before the point is suspected of reversal then a lower high for two times after the suspected point is a reversal for a bearish reversal. Meanwhile, a bullish reversal is the occurrence of a lower low twice before the point that is suspected of being reversal, then a higher low for two times after the point that is suspected of being a reversal. The five candles are used to determine the reversal point regardless of whether it is bullish or bearish.

Based on the four grand theories, it can be concluded that the steps to use the Astronacci method in determining the timing of future reversal are the formulations of the first research problem. Meanwhile, the second research problem formulation is obtained based on three Grand theories, namely the grand theories of financial astrology factors and how to determine Astrology factors that have an influence on stock prices and the Fibonacci method. By using the first research steps, the Astrology factors (moon phase, moon declination, planet aspect, ingress planet, and retrograde) will be tested which have the effect of JCI and Gold price. After obtaining the Astrology factor, it will be checked whether it has been confirmed by Fibonacci (the steps are in accordance with the results of the first study) so that the results of the second study are obtained. The formulation of the third problem is obtained based on the results of the second study which was continued to check the Fibonacci confirmation (according to the results of the first study). After determining the Astrology factors confirmed by Fibonacci (Astronacci), the Astronacci factor will be used to predict the date of future price reversals on JCI and Gold (2016).

Based on the grand theories that have been described, hypotheses and figures can be made in the framework of this research as in the following figure.

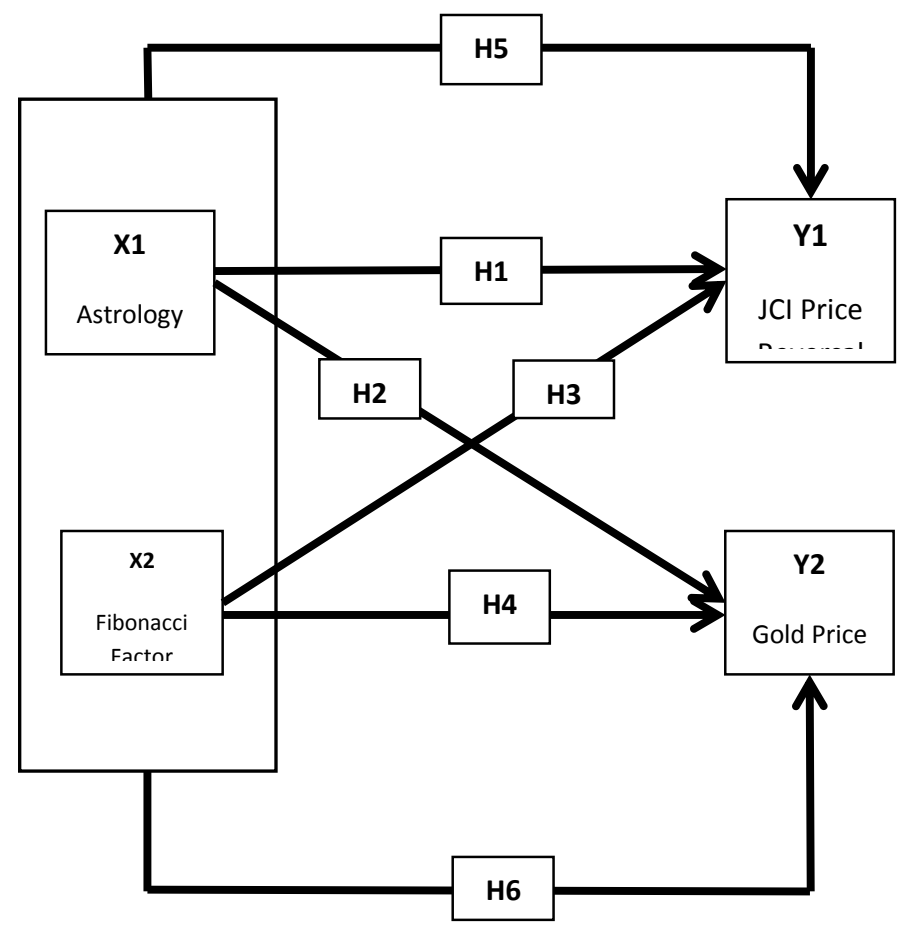

Figure 1 Research Framework 
In Figure $1, \mathrm{X}_{1}$ is the Astrology factor, $\mathrm{X}_{2}$ is Fibonacci, $\mathrm{Y}_{1}$ is the reversal of JCI, and $\mathrm{Y}_{2}$ is the reversal of Gold. There are 3 methods in this research, namely Astrology, Fibonacci, and Astronacci. The three methods are applied to determine the JCI reversal and the gold price. So that the hypothesis formed from this study is 6 . Based on the framework above, the Astrology factor JCI $\left(\mathrm{Y}_{1}\right)$ and the Gold price reversal $\left(\mathrm{Y}_{2}\right)$. Meanwhile, the Fibonacci factor $\left(\mathrm{X}_{2}\right)$ affects the reversal of the JCI price $\left(\mathrm{Y}_{1}\right)$ and the reversal of the Gold Price $\left(\mathrm{Y}_{2}\right)$. Meanwhile, $\mathrm{X}_{1}$ and $\mathrm{X}_{2}$ are called Astronacci (Astrology and Fibonacci) which affect the reversal of the JCI ( $\left.\mathrm{Y}_{1}\right)$ and the Gold Price Reversal $\left(\mathrm{Y}_{2}\right)$.

\section{METHODOLOGY}

The method used in this research is descriptive and explanatory methods. The descriptive method (based on previous research) is used to make steps in the Astrology, Fibonacci, and Astronacci method to find the date of the JCI reversal and the future price of Gold. While the explanatory method is used to apply the Astrology, Fibonacci, and Astronacci methods using historical data (2008-2017), JCI and the price of Gold. The three methods will be tested using the chi-square test to determine the effect of Astrology, Fibonacci, and Astronacci on JCI reversal. Based on the results of the chi-square test and the chance of a reversal, a future reversal date of JCI and Gold will be found (2018).

This type of research is a quantitative study that emphasizes theory testing through measuring research variables with numbers and analyzing data using statistical procedures. This quantitative approach aims to show the relationship between variables, provide descriptive statistics, estimate, and predict the results. The quantitative approach, in this case, is to process data to determine and predict the reversal of stock prices and gold prices, where the tools used are statistics with Chi-square.

The sample used in the study is the daily JCI data and the price of Gold for 1 decade or 10 years from 2008 to 2017. In 2008 there was a global crisis where there was an increase in inflation and a weakening of the rupiah exchange rate against the US dollar which had an impact on the weakening of the JCI (Rusbariand, Masodah, Riskayanto, \& Herawati, 2012). In 2013 there was a "perfect storm" phenomenon where several conditions merged and further aggravated the situation. The type of JCI reversal data is a discrete scale with two categories, namely 0 for no reversal and 1 for reversal. The type of data on the reversal of the Gold price is a discrete scale with two categories, namely 0 for no reversal and 1 for reversal. The type of astrology data is a discrete scale with 2 categories, namely 0 for no Astrology factors and 1 for Astrology factors.

The type of Fibonacci data is a discrete scale with two categories, namely 0 for absence or there is a Fibonacci time projection less than 3 and 1 for there is a Fibonacci time projection of more than 3.The Astronacci data type is a discrete in scale with two categories, namely 0 for no Astrology factors or factors occurring Astrology but does not occur or the Fibonacci time projection is less than 3 and 1 for Astrology factors and the Fibonacci time projection is more than 3 .

The method used in this research is descriptive and explanatory methods. The descriptive method (based on previous research) is used to make steps in the Astrology, Fibonacci, and Astronacci method to find the date of the JCI reversal and the future price of Gold. While the explanatory method is used to apply the Astrology, Fibonacci, and Astronacci methods using historical data (2008-2017), JCI and the price of Gold. The three methods will be tested in chi-square to determine the effect of Astrology, Fibonacci, and Astronacci on the reversal of JCI. Based on the results of the chi-square test and the chance of a reversal, a future reversal date of JCI and Gold will be found (2018). The chi-square test can be used to test whether there is a significant effect between two or more categories (comparative hypothesis) (Gani \& Amalia, 2015: 183).

\section{RESULT AND DISCUSSION}

\subsection{The Effect of Astrology on the JCI Reversal}

There are five steps in using the Astrology method for price reversal. The first step is to determine the Astrology factors. In this study, 5 Astrology factors were used, namely moon phase, moon declination, planet aspect, planet ingress, and retrograde. The following is a detail of each Astrology factor that is thought to have an influence on the JCI reversal. 
Moon Phase and Planet Aspect have a significant effect on JCI reversal with p-values of 0.003823 for Moon Phase and 0.001295 for Planet Aspect, respectively. Based on Table 1, it can be seen that the moon phase and planet aspect affect the JCI reversal. This can be seen from the p-value which is less than the significance value. The chance of JCI reversal based on its effect with the moon phase (by 17\%) is greater than planet aspect (by $14 \%$ ). 
Table 1 The Effect of Astrology Factor with the JCI Reversal

\begin{tabular}{|c|c|c|c|c|c|}
\hline Astrology Factors & Reversal & $\begin{array}{c}\text { Not } \\
\text { Reversal }\end{array}$ & $\begin{array}{l}\text { Percentage } \\
\text { of Reversal }\end{array}$ & $\begin{array}{c}\text { p-value } \\
\text { (Chi-square } \\
\text { Test) }\end{array}$ & Result \\
\hline Moon Phase & 41 & 206 & $17 \%$ & 0,003823 & Significant \\
\hline Moon Declination & 31 & 236 & $12 \%$ & 0,1409 & $\begin{array}{c}\text { Not } \\
\text { Significant }\end{array}$ \\
\hline Planet Aspect & 76 & 469 & $14 \%$ & 0,001295 & Significant \\
\hline Planet Ingress & 24 & 380 & $6 \%$ & 0,3322 & $\begin{array}{c}\text { Not } \\
\text { Significant }\end{array}$ \\
\hline Retrograde & 7 & 93 & $7 \%$ & 1 & \\
\hline
\end{tabular}

\section{The Effect of Astrology on the JCI Reversal}

There are five steps in using the Astrology method for price reversal. The first step is to determine the Astrology factors. In this study, 5 Astrology factors were used, namely moon phase, moon declination, planet aspect, planet ingress, and retrograde.

The effect of Astrology on Gold's reversal is shown in Table 5.20. Based on this table, it can be seen that the moon phase, moon declination and planet aspect have an influence on the reversal of the Gold price. The chance of a reversal is $19 \%$ (based on moon phase and moon declination) and 17\% based on planet aspect.

Table 2 The Effect of Astrology Factor with the Gold Price Reversal

\begin{tabular}{lccccc}
\hline $\begin{array}{c}\text { Astrology } \\
\text { Factors }\end{array}$ & Reversal & $\begin{array}{c}\text { Not } \\
\text { Reversal }\end{array}$ & $\begin{array}{c}\text { Percentage of } \\
\text { Reversal }\end{array}$ & $\begin{array}{c}\text { p-value (Chi-square } \\
\text { Test })\end{array}$ & Result \\
\hline Fibonacci & 29 & 39 & $43 \%$ & $5,247 \times 10^{-00}$ & Significant \\
\hline
\end{tabular}

Based on the table 4 above, it can be seen that the p-value is $5.247 \times 10^{-06}$ which is smaller than the level of significance $(p \leq 0,05)$. So that, it can be concluded that Fibonacci has an effect on the JCI reversal. Fibonacci has a significant effect on the reversal of the JCI price with a p-value of $5,247 \times 10^{-06}$ where $\mathrm{p}$-value is smaller than 0.05 .

Table 3. The Effect of Fibonacci Factor with the Gold Price Reversal

\begin{tabular}{cccccc}
\hline $\begin{array}{c}\text { Astrology } \\
\text { Factors }\end{array}$ & Reversal & $\begin{array}{c}\text { Not } \\
\text { Reversal }\end{array}$ & $\begin{array}{c}\text { Percentage } \\
\text { of Reversal }\end{array}$ & $\begin{array}{c}\text { p-value } \\
(\text { Chi-square } \\
\text { Test })\end{array}$ & Result \\
\hline Fibonacci & 45 & 74 & $42 \%$ & $\begin{array}{c}1,517 \\
\times 10^{-07}\end{array}$ & Significant \\
\hline
\end{tabular}

Based on the table above, it can be seen that the p-value is $4,587 \times 10^{-0 z}$ which is smaller than the level of significance $(p \leq 0,05)$. So that, it can be concluded that Fibonacci has an effect on the reversal of the gold price. Fibonacci has a significant effect on the reversal of the Gold price with a P-value of $1,517 \times 10^{-07}$ where $\mathrm{p}$-value is smaller than 0.05 . 


\subsection{The Effect of Astronacci on the JCI Reversal}

The Astronacci method is a combination of the Astrology and Fibonacci methods. Many of Astronacci's incidence of JCI reversals along with chi-square testing can be tabulated as in Table 6. Based on this table, it can be seen that planet aspect has the most reversal events (10 events).

Table 4 Number of JCI Reversals and Astronacci and Chi-square Test

\begin{tabular}{lccccc}
\hline \multicolumn{1}{c}{$\begin{array}{c}\text { Astrology } \\
\text { Factors }\end{array}$} & Reversal & $\begin{array}{c}\text { Not } \\
\text { Reversal }\end{array}$ & $\begin{array}{c}\text { Percentage } \\
\text { of Reversal }\end{array}$ & $\begin{array}{c}\text { p-value (Chi- } \\
\text { square Test) }\end{array}$ & Result \\
\hline Moon Phase & 7 & 4 & $64 \%$ & 0,0267 & Significant \\
$\begin{array}{l}\text { Moon } \\
\text { Declination }\end{array}$ & 2 & 4 & $33 \%$ & 0,4386 & Not \\
Planet Aspect & 10 & 9 & $53 \%$ & 0,0146 & Significant \\
Planet Ingress & 2 & 2 & $50 \%$ & 0,4142 & Significant \\
& & & & & Sot \\
Retrograde & 0 & 2 & $0 \%$ & NA & NA \\
\hline
\end{tabular}

In addition to the percentage value of JCI reversal based on Astronacci, the chi-square test also needs to be considered in determining the effect of Astronacci on JCI reversals. Based on the chi-square test, the p-value that is smaller than the significance value is Astronacci with the moon phase astrology factor (0.0267) and planet aspect (0.0146). So that Astronacci with the Astrology factors of the moon phase and planet aspect affect the JCI reversal. Astronacci has a significant effect on the reversal of JCI prices when Fibonacci is combined with the Astrology Moon Phase (0.0267), Planet Aspect (0.0146) factors. In addition, Astronacci also noted that the chance of a reversal will be more than 50\% compared to using only one of Fibonacci or Astrology.

\subsection{The Effect of Astronacci on the Gold Reversal}

The Astronacci method is a combination of the Astrology and Fibonacci methods. Many of Astronacci's incidents of reversal in Gold's price along with chi-square testing can be shown as follows.

Table 5 Number of Gold Reversals and Astronacci

\begin{tabular}{cccccc}
\hline Astronacci with & Reversal & $\begin{array}{c}\text { Not } \\
\text { Reversal }\end{array}$ & $\begin{array}{c}\text { Percentage } \\
\text { of Reversal }\end{array}$ & $\begin{array}{c}\text { p-value } \\
\text { (Chi- } \\
\text { square } \\
\text { Test })\end{array}$ & Result \\
Astrology factors & 7 & 6 & $54 \%$ & 0,0336 & Significant \\
\hline $\begin{array}{l}\text { Moon Phase } \\
\text { Moon }\end{array}$ & 11 & 10 & $52 \%$ & 0,0076 & Significant \\
\hline
\end{tabular}

Astronacci has a significant effect on the reversal of Gold's price when Fibonacci is combined with the Astrology factors of Moon Phase (0.0336), Moon Declination (0.0076), and Planet Aspect (0.0022). In addition, Astronacci also noted that the chance of a reversal will be more than $50 \%$ compared to using only one of Fibonacci or Astrology.

\subsection{Determination of a future JCI Reversal Date}

This study examines the effect of Astrology, Fibonacci, and Astronacci methods on the reversal of JCI. Based on the test of this effect, one method that has an influence with the JCI reversal is chosen and has the highest chance. The summary of testing the effect of the three methods and the chances of a JCI reversal can be table as follows.

Table 6 The Comparison of Three Methods to the JCI Reversal 


\begin{tabular}{|c|c|c|c|c|c|}
\hline Factor & Reversal & $\begin{array}{c}\text { Not } \\
\text { Reversal }\end{array}$ & $\begin{array}{l}\text { Percentage } \\
\text { of Reversal }\end{array}$ & $\begin{array}{c}\text { p-value }(C h i- \\
\text { square Test) }\end{array}$ & Result \\
\hline Without Method & 189 & 2235 & $8 \%$ & & \\
\hline \multicolumn{6}{|l|}{ Astrology } \\
\hline Moon Phase & 41 & 206 & $17 \%$ & 0,003823 & Significant \\
\hline Moon Declination & 31 & 236 & $12 \%$ & 0,1409 & Not Significant \\
\hline Planet Aspect & 76 & 469 & $14 \%$ & 0,001295 & Significant \\
\hline Planet Ingress & 24 & 380 & $6 \%$ & 0,3322 & Not Significant \\
\hline Retrograde & 7 & 93 & $7 \%$ & 1 & Not Significant \\
\hline Fibonacci & 29 & 39 & $43 \%$ & $5,247 \mathrm{E}-06$ & Significant \\
\hline \multicolumn{6}{|l|}{ Astronacci } \\
\hline Moon Phase & 7 & 4 & $64 \%$ & 0,02669 & Not Significant \\
\hline Moon Declination & 2 & 4 & $33 \%$ & 0,4386 & Not Significant \\
\hline Planet Aspect & 10 & 9 & $53 \%$ & 0,01457 & Not Significant \\
\hline Planet Ingress & 2 & 2 & $50 \%$ & 0,4142 & Not Significant \\
\hline Retrograde & 0 & 2 & $0 \%$ & NA & NA \\
\hline
\end{tabular}

Based on Table 6, it can be seen that the methods that have a significant effect on JCI reversal include Astrology (with moon phase and planet aspect factors), Fibonacci, and Astronacci (with moon phase and planet aspect Astrology factors). Based on this method, the method that has the highest chance of reversal in JCI is the Astronacci method with moon phase factors (64\% chance) and planet aspect (53\%). Meanwhile, the Astrology method with moon phase factor (17\% chance) and planet aspect (12\%) and the Fibonacci method has a $43 \%$ chance.

Based on the Astronacci method, with the moon phase and planet aspect factors, the future date of JCI direction reversal can be determined (2018) including February 2; June 27, 28 and 29; December 17 to 21.

\begin{tabular}{|l|c|c|c|c|l|}
\hline \multicolumn{1}{|c|}{ Factor } & Reversal & $\begin{array}{c}\text { Not } \\
\text { Reversal }\end{array}$ & $\begin{array}{c}\text { Percentage of } \\
\text { Reversal }\end{array}$ & $\begin{array}{c}\text { p-value (Chi- } \\
\text { square Test) }\end{array}$ & \multicolumn{1}{|c|}{ Result } \\
\hline Method-less & 268 & 2631 & $9 \%$ & & \\
\hline Astrology & 48 & 199 & $19 \%$ & 0,001258 & Significant \\
\hline Moon Phase & 52 & 215 & $19 \%$ & 0,001361 & Significant \\
\hline Moon Declination & 98 & 480 & $17 \%$ & 0,0001822 & Significant \\
\hline Planet Aspect & 13 & 194 & $6 \%$ & 0,3575 & $\begin{array}{l}\text { Not } \\
\text { Significant }\end{array}$ \\
\hline Planet Ingress & 16 & 84 & $16 \%$ & 0,1995 & $\begin{array}{l}\text { Not } \\
\text { Significant }\end{array}$ \\
\hline Retrograde & & & & &
\end{tabular}




\begin{tabular}{|c|c|c|c|c|l|}
\hline \hline Fibonacci & 45 & 74 & $42 \%$ & $1,517 \mathrm{E}-07$ & $\begin{array}{l}\text { Ásearch Articte } \\
\text { Significant }\end{array}$ \\
\hline Astronacci & 7 & 6 & $54 \%$ & 0,03362 & Significant \\
\hline Moon Phase & 11 & 10 & $52 \%$ & 0,007581 & Significant \\
\hline Moon Declination & 17 & 22 & $44 \%$ & 0,00219 & Significant \\
\hline Planet Aspect & 4 & 4 & $50 \%$ & 0,2807 & $\begin{array}{l}\text { Not } \\
\text { Significant }\end{array}$ \\
\hline Planet Ingress & 4 & 4 & $50 \%$ & 0,2807 & $\begin{array}{l}\text { Not } \\
\text { Significant }\end{array}$ \\
\hline Retrograde & & & & & \\
\hline
\end{tabular}

Table 7 The Comparison of Three Methods to Reversal Gold

Based on Table 7, it can be seen that the methods that have a significant effect on the reversal of the Gold price include Astrology (with moon phase, moon declination and planet aspect factors), Fibonacci, and Astronacci (with moon phase astrology factors, moon declination and planet aspect). Based on this method, the method that has the highest chance of predicting Gold's reversal is the Astronacci method.

The reversal of the Gold price is the Astronacci method with moon phase factors (54\% chance), moon declination (44\% chance) and planet aspect (52\% chance). Meanwhile, the Astrology method with moon phase (19\% chance), moon declination (19\% chance) and planet aspect (17\% chance) as well as the Fibonacci method has a chance of $42 \%$.

Based on the Astronacci method, with the moon phase, moon declination and planet aspect factors, the future date of the reversal of the Gold price can be determined (2018) including January 29, 30, 31; February 1, 25, 26; April 4, 5, 6, 10, 11, 12; June 26 to 29; July 8th to 13th; October 11, 12, 14, 15, 16.

\section{CONCLUSIONS}

1. Astrology factors that have the greatest chance of reversal of JCI include moon phase (17\%), planet aspect $(14 \%)$, moon declination $(12 \%)$, retrograde $(7 \%)$, and planet ingress $(6 \%)$. The chances of a JCI reversal in each of the Astrology factors are not good, because it is below 50\%. Based on the results of the chi-square test, it can be concluded that the Astrology factors of the moon phase and planet aspect affects the JCI reversal.

2. Astrology factors that have the greatest chance of reversing the Gold price include moon phase (19\%), moon declination (19\%), planet aspect (17\%), retrograde (16\%), and planet ingress $(6 \%)$. The chance of a reversal in the Gold price in each of the Astrology factors is not good, because it is below 50\%. Based on the results of the chi-square test, it can be concluded that the Astrology factors of the moon phase, moon declination and planet aspect affect the reversal of the Gold price.

3. The chance of JCI reversal using the Fibonacci method is 43\%. The chance of a JCI reversal using Fibonacci is not good, because it is below 50\%. Based on the results of the chi-square test, it can be concluded that Fibonacci affects the JCI reversal.

4. The chance for a reversal of the Gold price using the Fibonacci method is $38 \%$. The chance of a reversal in the Gold price using Fibonacci is not good, because it is below 50\%. Based on the results of the chi-square test, it can be concluded that Fibonacci has an effect on the reversal of the gold price.

5. Astronacci, which has the greatest chance of reversal of JCI, is the moon phase astrology factor (64\%), planet aspect (53\%), planet ingress $(50 \%)$, moon declination (33\%), and retrograde $(0 \%)$. The best chance of a JCI reversal using Astronacci is the moon phase astrology factor, planet aspect, and planet ingress because it is above $50 \%$. Based on the results of the chi-square test, it can be concluded that Astronacci with the moon phase and planet aspect astrology factors affects the JCI reversal.

6. Astronacci, which has the greatest chance of reversing the Gold price, is the Astrology factor of the moon phase (54\%), moon declination (52\%), planet ingress (50\%), retrograde 50\%, and planet aspect (44\%). The best chance of a reversal in Gold's price using Astronacci is the moon phase astrology, moon declination, ingress planet, and retrograde because it is above $50 \%$. Based on the results of the 
chi-square test, it can be concluded that Astronacci with the moon phase Astrology factor and planet aspect affects the reversal of the gold price.

\section{Literature}

[1] Admiranto, A. G. (2009). Menjelajahi Tata Surya. Yogyakarta: Kanisius.

[2] Brown, C. (2008). Fibonacci Analysis (Bloomberg Market Essentials: Technical Analysis) (Brown). New York: Bloomberg Press.

[3] Bucholtz, M. G. (2013). The Bull, The Bear and The Planets: Trading the Financial Markets Using Astrology. Bloomington: iUniverse.

[4] Denny, M. W., \& Gaines, S. D. (2007). Encyclopedia of Tidepools and Rocky Shores. California: The Regents of the University of California Press.

[5] Dichev, I. D., \& Janes, T. D. (2001). Lunar Cycle Effects in Stock Returns (SSRN Scholarly Paper No. ID 281665). Rochester, NY: Social Science Research Network. Retrieved from https://papers.ssrn.com/abstract=281665

[6] Fischer, R. (1993). Fibonacci Applications and Strategies for Traders: Unveiling The Secret of The Logarithmic Spiral. United States: John Wiley \& Sons.

[7] Floros, C., \& Tan, Y. (2013). Moon Phases, Mood and Stock Market Returns: International Evidence. Journal of Emerging Market Finance, 12(1), 107-127. https://doi.org/10.1177/0972652712473405

[8] Kirkpatrick, C. D., \& Dahlquist, J. R. (2011). Technical Analysis: The Complete Resource for Financial Market Technicians (2nd ed.). New Jersey: Pearson Education.

[9] Lusia, D. A., \& Muntari. (2016). Perbandingan Risk dan Return Investasi Saham Indonesia, Gold, dan EURUSD dengan Inflasi, 2(2), 8-16.

[10] Merriman, R. A. (2015). Solar Lunar Keys to Gold Prices: Market Timing Secrets of A Gold Trader. United States: Seek It Publications.

[11] Pasavento, L., \& Smoleny, S. (2015). A Traders Guide to Financial Astrology: Forecasting Market Cycles Using Planetary and Lunar Movements. John Wiley \& Sons.

[12] Periasamy, P. (2009). Financial Management. Tata McGraw-Hill Education.

[13] Pesavento, L. (1997). Astro-Cycles: The Trader's Viewpoint. Greenville: Traders Press.

[14] Pring, M. J. (2014). Technical Analysis Explained: The Successful Investor's Guide to Spotting Investment Trends and Turning Points (Fifth). New York: McGraw Hill Professional.

[15] Rusbariand, S. P., Masodah, Riskayanto, \& Herawati, S. (2012). Analisis Pengaruh Tingkat Inflasi, Harga Minyak Dunia, Harga Emas Dunia, Dan Kurs Rupiah Terhadap Pergerakan Jakarta Islamic Index Di Bursa Efek Indonesia. Forum Bisnis \& Keuangan (Vol. I, hlm. 724-740). Retrieved from http://riskayanto.staff.gunadarma.ac.id/Publications

[16] Uludag, B. K., \& Lkhamazhapov, Z. (2016). The volatility dynamics of spot and futures Gold prices: Evidence from Russia. Research in International Business and Finance, 38, 474-484. https://doi.org/10.1016/j.ribaf. 2016.07.003

[17] Weingarten, H. (2000). Investing by the Stars: Using Astrology in the Financial Markets (2nd ed.). New York: Traders Press.

[18] Yuan, K., Zheng, L., \& Zhu, Q. (2006). Are investors moonstruck? Lunar phases and stock returns. Journal of Empirical Finance, 13(1), 1-23. https://doi.org/10.1016/j.jempfin.2005.06.001

[19] Zulfikar. (2016). Introduction to the Capital Market with a Statistical Approach. Yogyakarta: Deepublish.

7. Authors

1. Gema Merdeka Goeyardi, He is the president and founder of Astroancci International, LLC www.astronacci.com. He is studying Doctoral of Finance in University YAI Jakarta, Indonesia. Gema has been using technical analysis for more than 10 years ass investor, broker, analyst, and instructor. He 
invented his method called Astronacci. This is the combining method between financial astrology and Fibonacci to find the market timing and future price road-map prediction.

2. Ghozali Imam, He completed his Bachelor of Economics education majoring in Accounting at Gadjah Mada University, Yogyakarta 1985. He completed his Masters in the University of New South Wales, Sydney, Australia 1990 and his doctoral education (PhD) in Management Accounting was completed at the University of Wollongong, Australia 1995. He is a professor in accountancy of Diponegoro University. He is also the lecturer of University YAI Jakarta, Trisakti University, and Tanjungpura University.

3. Hamdy Hady, He was appointed as Permanent Professor of the Postgraduate Program at the Persada Indonesia University YAI Jakarta since 2005. He received Master and Doctoral degree in International Financing Economics from Universite de Paris XIII. His concentration in the fields of Strategic Management, Marketing Management, International Marketing, Financial Management, International Finance, Marketing and Investment Seminar. 